\title{
GABINETES DE CURIOSIDADES E OS PRIMÓRDIOS DA ILUSTRAÇÃO CIENTÍFICA
}

\author{
Rosa Maria Alves Pereira
}

\section{Resumo}

Os Gabinetes de Curiosidades, especialmente o de Albertus Seba, contribuíram para o desenvolvimento cultural a partir do século XVII na Holanda. Com o tempo, a própria imagem desses objetos colecionados passou a ser a síntese do conhecimento sobre História Natural.

O surgimento da ilustração científica promoveu questionamentos sobre as diferentes visões de mundo reunindo a ciência e a arte, enquanto a Europa - imersa em um planeta em processo de transformação - voltava-se para conhecer um Novo Mundo recém-descoberto.

Palavras-Chave: Ilustração científica, colecionismo

\begin{abstract}
The Curiosity Cabinets, especially that of Albertus Seba, contributed for the Dutch cultural development in the $17^{\text {th }}$ century. With the time, the own image of these collected objects started to be the synthesis of the knowledge of Natural History.

The start of the scientific illustration promoted questionings about the different visions of world gething the science and the art, while Europe - immersed in a planet in transformation process - was turned to know just-discovered a New World.
\end{abstract}

\section{Os objetos como documentos históricos e sua iconografia}

Os seres humanos têm a capacidade de selecionar (separar o que merece ser guardado), estabelecer relacionamentos entre si e a materialidade, produzir conhecimentos e difundi-los; acumular informações e inserir-se culturalmente em sociedade. A maneira como o homem se relaciona com a natureza está ligada ao estágio de desenvolvimento sóciocultural da humanidade e ao legado de conhecimentos adquiridos da cultura material e preservados como documentos históricos.

A partir do século XVI foram surgindo os Gabinetes de Curiosidades, que eram amplos salões destinados a abrigar as coleções de História Natural. Esses acervos pertenciam aos colecionadores, que eram, na maioria das vezes, membros da nobreza e os objetos eram oriundos das expedições ao Novo Mundo.

Essa grande variedade de objetos por si só carregam uma linguagem a ser decifrada. Um acervo pode reconstruir para nós a história que os objetos guardados têm para contar com a sua presença nesses gabinetes. A partir do acúmulo desses "achados e guardados" nessas coleções de objetos curiosos, a compreensão do mundo realmente mudou e a História Natural pôde desenvolver-se como "ciência moderna".

Embora os Gabinetes reunissem também objetos produzidos pelo homem, me deterei naqueles que foram coletados diretamente da natureza (Naturalia) e procurarei identificar o papel de suas representações iconográficas.

A seção Naturalia contava com o maior número de exemplares. O Reino Vegetal, impulsionado pelas supostas ações curativas de seus espécimes e pela relativa capacidade de conservação (se comparado aos espécimes do Reino Animal), era

\footnotetext{
${ }^{1}$ Especialista em História da Cultura e da Arte pela Universidade Federal de Minas Gerais.
} 
representado em herbários e jardins anexos aos gabinetes com plantas conservadas em seu estado natural (vivas e aclimatadas) ou secas ${ }^{2}$.

A curiosidade sempre desempenhou um papel importante na busca do conhecimento e na formação de nosso imaginário. Está ligada às escolhas que fazemos para montarmos a nossa "coleção de imagens mentais", da qual muitas vezes a emoção participa como um fixador da memória pessoal e coletiva na fruição dos bens culturais.

As expedições de conquista territorial efetivadas pelos navegadores, especialmente entre os séculos XV ao XVII, trouxeram uma nova visão de mundo por ter acrescentado ao inventário de História Natural inúmeros espécimes apropriados (saqueados, por que não dizer?) e levados do Novo Mundo à Europa, até chegarem nas cidades portuárias para o entretenimento de uns poucos, provocado pelo exotismo dos Gabinetes de Curiosidades.

Preservadores de um saber em construção, os colecionadores dispunham de dois tipos básicos de coleção: a de objetos retirados da natureza e a de artefatos produzidos pelo homem. Principalmente a segunda perdurou, pois estabeleceu-se uma associação com obras de arte, mesmo utilizando conchas ou a escultura em algum tipo de chifre de animais ou pedras... resta saber se o motivo foi o valor econômico que essas peças foram adquirindo com a seleção e exposição feita pelo colecionador.

Amsterdam abrigava uma dessas coleções - a de um boticário. Era uma cidade que além de ter uma intensa atividade portuária, dispunha de uma cultura iconográfica, de uma pintura e de um desenho de observação naturalista invejável, pois o artista passou a sair do atelier e das corporações de ofício para buscar a paisagem, a cartografia das cidades, em rápido crescimento, os animais e as plantas em decorrência da tradição agrária holandesa.

As narrativas e as descrições das Américas, recém-descobertas, são misturadas e geram um saber que vão das palavras aos desenhos, dos livros a outros objetos. Até uma simples pedra ganha importância por estar exposta ou por ter sido guardada como testemunha representativa de um lugar distante.

\section{As coleções de História Natural}

As coleções reunidas nos gabinetes resultaram do trabalho dos coletores dos séculos XVI e XVII. Na maioria dos casos, esses objetos foram gravados e indicados de modo organizado, mesmo se os critérios, às vezes, subjetivos para a classificação sistemática diferiam de uma coleção para uma outra.

O caráter efêmero das coleções, o modo como foram se formando e se perdendo fizeram com que o colecionador cuidasse de registrar seu inventário para mantê-las por mais tempo, através das representações iconográficas de seus tesouros.

A preservação das coleções lembra um incansável vôo de Ícaro. Ao buscar a totalidade do "conhecimento - luz", suas delicadas asas se desfaziam. As coleções com o tempo iam se deteriorando, e o "colecionador-Ícaro" tentava, em vão, recolher suas penas em pleno vôo. A transitoriedade da vida estava presente nas coleções de História Natural, e com a morte do colecionador várias coleções se dispersaram.

\footnotetext{
2 POSSAS, Helga Cristina Gonçalves. Classificar e ordenar: os gabinetes de curiosidades e a história natural. IN: FIGUEIREDO, Betânia G. e Diana Gonçalves Vidal (org.) MUSEUS dos Gabinetes de Curiosidades à Museologia Moderna. Belo Horizonte: Argumentum, 2005, p. 154.
} 


\section{Imagens artísticas e imaginário}

Em nossa trajetória social elaboramos um conjunto de representações advindo do imaginário que compõe-se das percepções de mundo. A elaboração das memórias individuais constitui-se através de mecanismos diversos, inclusive o uso e apropriação das imagens, que, uma vez compartihadas, tornam-se memórias coletivas - imagens híbridas de um tempo, de uma parte do mundo ou de um modo de vê-lo.

A cultura sempre utilizou as imagens para a manutenção de seus valores, e quanto mais realistas menos encontraram resistências em serem acreditadas, embora as imagens também tenham descrito alguns seres mitológicos e lendários, presentes no imaginário europeu daquele tempo como, por exemplo, a bidra ${ }^{3}$ (bicho-de-sete-cabeças).

Em outros momentos, as ilustrações documentavam flores e eram reunidas em luxuosos livros de ilustração botânica decorrentes do desenvolvimento do desenho como arte prática o que possibilitou aos herbanários a identificação das plantas que usavam para seus medicamentos. A ilustração botânica esteve sempre ligada ao desenvolvimento da ciência (a recíproca também é verdadeira), desde o tempo das grandes navegações, da descoberta do Novo Mundo e de novas espécies vegetais.

\section{A representação iconográfica da História Natural na Holanda do século XVII}

Os olhos são para ver e o que os olhos vêem só o desenho sabe. José da Amalda Negreiros, artista plástico português

Para Foucalt, a história natural é o espaço aberto na representação por uma análise que se antecipa à possibilidade de ver o que se poderia dizer.

A Holanda, desde a década de 1580, estava consolidada como principal centro de botânica e agricultura. Até mesmo os holandeses que emigraram para a Inglaterra cultivavam flores e participavam das festas anuais dos floristas que ocorriam desde meados do séc. XVII ${ }^{4}$. Era intenso o comércio de flores entre a Holanda, Inglaterra e a França, sendo os holandeses os maiores vendedores.

Era comum, ainda nessa época, que o mesmo espécime animal ou vegetal recebesse nomes diferentes em diversos lugares da Europa. Alguns catálogos botânicos estavam sendo confeccionados com a utilização da gravura em metal e da litografia, o que permitia grandes tiragens e a disseminação das imagens florísticas (florilégios) ${ }^{5}$ e zoológicas. A classificação do mundo natural com nomenclatura em gênero e espécie, foi proposta por Linné (17071778), apenas em meados do século XVIII. Nem todos artistas, contudo, tiveram a oportunidade de fazer as observações in loco.

Os holandeses tinham a tradição de fazer registros pictóricos, não-verbais. $\mathrm{Na}$ equipe de Maurício de Nassau, por exemplo, incluíram-se observadores e descritores peritos em História Natural, em Cartografia, em Desenho e Pintura: Para Alpers, Eles reuniram um registro pictórico único da terra brasileira, seus habitantes, sua flora e suas coisas exóticas ${ }^{6}$. Um marco inicial da pintura de paisagens no Brasil pode ser encontrado nos pintores que chegaram ao país com Maurício de Nassau, como Albert Eckhout (1610-1666) e sobretudo Frans Post (1612-1680).

\footnotetext{
${ }^{3}$ SEBA, Albertus. Natural Curiosities from the Cabinet of Albertus Seba. London: Taschen, 2003, p.13.

${ }^{4}$ KEITH, Thomas. O Homem e o Mundo Natural. São Paulo: Cia. das Letras, 1988, p. 270.

5 Florilégios eram gravuras encomendadas por príncipes ou naturalistas das flores de seus jardins ou de suas coleções particulares reunidas em estufas.

${ }^{6}$ ALPERS. Op. cit. p. 309.
} 
A cultura do exótico e o esforço classificatório do mundo natural estavam também presentes nas pinturas e gravuras da época: das naturezas mortas, as flores traduziam a transitoriedade da vida e as paisagens, uma tentativa de mapear o território e dominar a natureza. Os artistas daquela época se rendiam aos detentores do poder e, sob encomenda, representavam em suas obras a opulência dos jardins de seus palácios e de suas coleções de diversos objetos vindos de todas as partes do mundo.

\title{
Descarregando informações
}

A chegada de um navio no porto de Amsterdam era um acontecimento importante, pois além de trazer mercadorias, também descarregava informações sobre o Novo Mundo - os europeus eram ávidos por conhecimentos e relatos de aventuras vividas (ou imaginadas) por aqueles homens corajosos que singravam os mares.

As relações de troca nessas ocasiões além de comerciais (os marujos vendiam aos colecionadores as plantas e animais), foram também humanas, de comunicação, gerando operações de adição/subtração ao nível da materialidade e de divisão/multiplicação entre culturas, saberes distintos e complementares colocados em contato definitivamente.

Um dos colecionadores mais notáveis da Holanda foi o boticário Albertus Seba, que reuniu uma das maiores coleções de História Natural de que se tem notícia.

\section{A coleção de História Natural de Albertus Seba}

\begin{abstract}
O Gabinete de Curiosidades naturais de Albertus Seba (1666-1736), autêntico tesouro de história natural, é único em seu gênero. Se o farmacêutico de Amsterdam começou a colecionar com fins científicos especiais da fauna e flora de todo o mundo, imediatamente sua paixão de colecionador o levou a desconsiderar os limites usuais da disciplina farmacêutica. Sua recompilação, que gozou de fama internacional ainda em vida, chegou a ter a diversidade extraordinária: desde insetos procedentes de países longínqüos, serpentes de brilhos irisados e crocodilos até animais fantásticos como a "hidra" de sete cabeças ${ }^{7}$.
\end{abstract}

As coletas de animais e plantas se estenderam por décadas, e a partir de 1731, e por encomenda de Seba, os variados objetos de sua coleção começaram a ser desenhados por uma equipe de artistas-desenhistas.

Essas ilustrações foram publicadas mais tarde, acompanhadas de um comentário explicativo, em uma obra de quatro volumes intitulada LOCCUPLETISSIMI RERUM THESAURI ACCURATA DESCRIPTIO. Essa obra, de grande formato, compreendia a quantidade de 446 pranchas de cobre e foi publicada entre 1734 e 1765. As ilustrações foram iniciadas em 1731 e após a morte de Seba (1736) a obra continuou por mais alguns anos, porém ainda ficou inacabada. Não somente a qualidade estética das ilustrações era incomum para a época; é notável a fidelidade das representações científicas dos animais e plantas que são apresentadas de modo cênico. Os quatro volumes da coleção de Seba demonstram os conhecimentos de História Natural daquela época.

O primeiro reúne as ilustrações de plantas e animais coletados no Novo Mundo, mais precisamente na América do Sul e na Ásia. Os animais representados eram pássaros, anfíbios, aracnídeos, lagartos e até dragões. O segundo volume foi dedicado às serpentes, apresentadas de forma estética e simétrica, algumas representadas em meio ao seu habitat, em meio às plantas e alguns animais, os quais supostamente lhes serviam de alimento. $O$

${ }^{7}$ SEBA, Albertus. Natural Curiosities from the Cabinet of Albertus Seba. London: Taschen, 2003, p. 13. 
ambiente marinho pode ser observado no volume três, que carrega uma profusão de imagens de conchas de moluscos, dispostas em ornamentações sui generis, além de peixes, estrelas do mar, polvos, crustáceos e ouriços. Em seu último volume, os insetos aparecem juntamente com fósseis e minerais do Gabinete de Sebas. Destacam-se entre os insetos, as borboletas e mariposas, também apresentadas em seus estágios de lagarta e pupa. Algumas dessas borboletas foram provavelmente originárias do Brasil ou pelo menos da América tropical, como reconheceu o professor e entomólogo Ângelo Machado, do Instituto de Ciências Biológicas da Universidade Federal de Minas Gerais.

A grande quantidade de espécies da fauna e da flora é fruto de uma vida inteira dedicada à coleção. Para a publicação dos catálogos, de excelente qualidade gráfica, os editores contaram com o trabalho de 13 artistas-gravadores, que se ocuparam por trinta anos (1734-1765) em transferir os desenhos para as pranchas, elaborar as capas e fazer o retrato de Albertus Seba.

\section{A versatilidade e a importância de Albertus Seba ${ }^{8}$}

O boticário e comerciante Seba conquistou um grande prestígio com o seu comércio que denominava A farmacopéia alemã. Ocupava-se da botica de viagem dos barcos que saiam de Amsterdam, assim como de tratar dos marinheiros. Quando um barco atracava no porto, Seba apressava-se para cuidar dos marinheiros e conseguia comprar a um bom preço os objetos que chegavam de países longínqüos, ou os obtinha em troca de medicamentos.

Além de excelente comerciante, podemos também apresentar Seba como um divulgador científico, um comunicador. Assumindo o papel de jornalista-publicitário, ele publicava anúncios em seu periódico de Amsterdam com indicação do preço de suas drogas e matérias-primas de fármacos. O comerciante-comunicador destinava suas publicações a um público internacional de pesquisadores da natureza, colecionadores e amantes dos livros. Ele também desempenhou a função de escritor, pelo menos no primeiro volume de seu Thesaurus. Como editor, investiu na publicação das ilustrações com atenção especial à legibilidade dessas imagens através de uma busca incansável de classificação dos gêneros com rigor científico e cuidadosa representação de animais e plantas nas ilustrações das pranchas naturalistas. Como distribuidor das publicações, cuidou de fazer edições bilíngües e de dar mobilidade e visibilidade à sua coleção através dos catálogos que circularam por toda a Europa.

Os representantes dos editores e Seba se dispuseram a publicar o gabinete do colecionista em uma grande obra. Este acordo foi assinado em 30 de outubro de 1731, em Amsterdam. (Ao todo, os quatro volumes do Thesaurus continham 446 pranchas, 175 delas duplas).

As numerosas ilustrações cuja elaboração ocupou muito tempo, foram publicadas inicialmente em preto e branco. Não se sabe se as editoras haviam oferecido também uma edição colorida, que naturalmente aumentava o preço de capa e o apelo mercadológico.

\footnotetext{
8 Albertus Seba (1665-1736) nasceu em Etzel (Frisia Oriental) e escolheu a profissão de farmacêutico, um ofício intimamente relacionado com os estudos de História Natural. Naquele tempo, os medicamentos não eram fabricados sinteticamente como hoje em dia, mas eram obtidos mesclando-se elementos naturais. Para conseguir as substâncias curativas de animais, plantas e minerais se dispunha de toda uma série de receitas tradicionais dos quatro pontos cardeais, cujas possíveis aplicações eram estudadas e ensaiadas. Em muitos casos a paixão colecionista e investigadora se emancipava do uso meramente farmacêutico. Numerosos boticários criaram coleções de História Natural respeitáveis, contribuindo assim para um melhor conhecimento da Natureza.
} 


\begin{abstract}
A riqueza das cores é um verdadeiro prazer; o colorido não só elevava o atrativo estético como também o valor científico. Por exemplo, alguns exemplares de mariposas, serpentes e moluscos só são distinguidos com a ajuda da cor, enquanto em preto e branco é muito difícil reconhecer as diferenças entre alguns animais. Com ou sem cor, o Thesaurus é em todo caso um exemplo impressionante da arte barroca e da imprensa. As pranchas dos volumes II e IV respondem cada vez mais à representação científica usual daquela época. Os animais são cuidadosamente representados e classificados por gêneros. ${ }^{9}$.
\end{abstract}

Muitas criaturas da coleção de Seba eram desconhecidas, algumas até já extintas, eram tão curiosas na época de Seba como ainda nos são hoje. Para Svetlana Alpers, nenbuma outra cultura reuniu tantos conbecimentos através de imagens como os holandeses ${ }^{10}$.

\title{
Os primórdios da ilustração científica
}

Entre os séculos XVI e XVII, algumas imagens artísticas eram consideradas como documentos científicos. Mas a ilustração científica só pôde florescer com a invenção da imprensa. Anteriormente, quando a reprodução dos textos era feita por copistas, as ilustrações neles inseridas não eram reproduzidas com fidelidade.

Vários condicionantes históricos permitiram que se desenvolvesse a ilustração científica moderna nos últimos cinco séculos. Quando regressavam de suas viagens, os exploradores e os naturalistas pretendiam descrever os animais que encontraram na África e nas Américas, as plantas de onde provinham as especiarias que traziam a bordo, as cores exóticas com as quais se pintavam os nativos do Novo Mundo e os lugares por onde passaram. A descoberta de uma nova natureza encontrou na imprensa e nas técnicas da perspectiva um meio adequado à sua difusão pelo mundo europeu, que assim puderam participar das viagens junto aos que ousaram enfrentar os mares.

Hoje, ao contrário de reproduções artísticas motivadas por preocupações quase exclusivamente estéticas, as ilustrações científicas ocupam-se em contar uma história, em descrever uma realidade, inserindo cortes, perspectivas variadas e anotações explicativas.

A ilustração científica ocupa um lugar em que a ciência e a arte se misturam. $\mathrm{Na}$ busca por dissecar a realidade da natureza, ela apresenta uma ótica artística fiel, dentro de uma nova ética científica. Dos pincéis e aquarelas, chega-se ao século XX e XXI com novos recursos de linguagens incluindo a documentação digital, novas mídias e equipamentos que ampliaram o campo de percepção do olho humano.

\section{Dos Gabinetes à Multimídia}

As linguagens representam uma forma de transcrição do conhecimento. As gravuras feitas por encomenda de Seba, traduziam com fidelidade os objetos de sua coleção, pois eram desenhadas a partir de uma observação direta do original. Seba como comunicador estava a frente de seu tempo e agia como um artista multimídia atual:

Engana-se quem pensa que o conceito de multimídia é recente. Sua origem data de centenas de anos antes da invenção do computador, da TV e do vídeo. $\mathrm{Na}$ verdade, surgiu no Renascimento, nos séculos 16 e 17, no afã de conhecimento criado pelas primeiras enciclopédias ${ }^{11}$.

\footnotetext{
${ }^{9}$ http://www.ejournal.unam.mx/ciencias/no68/CNS06809.pdf.

10 ALPERS. Op. cit. p. 310.

11 http://www1.folha.uol.com.br/folha/ilustrada/ult90u25200.shl, de 29/06/2002 - 09h52 IN: Biblioteca Pública de NY tenta reproduzir câmera de curiosidades (da Folha de S. Paulo, sucursal de Nova York).
} 
O trabalho do colecionador extrapolava o de um dedicado resgatador de objetos contra a ação do tempo. Ele cuidava de demarcar o mundo em relação ao que merecia a permanência e o que poderia ser simplesmente descartado do universo das representações. E os catálogos das coleções acabaram por salientar o papel das imagens como guardiãs da memória; o signo substitui gradativamente o significante quando, ao imprimir os livros ilustrados sobre as coleções, estas vão perdendo os visitantes, que passam a migrar para os catálogos. Hoje temos acesso a esse acervo através das ilustrações elaboradas ao longo dos anos por artistas dedicados... As imagens da natureza vão muito além da fauna e flora. Faz parte do imaginário atribuir à natureza os elementos como paisagem, territórios e posturas corporais e indumentária dos habitantes retratados nas gravuras e pinturas da época.

Vejo as imagens como importantes documentos históricos, pois são uma fonte capaz de revelar representações que o texto escrito não traduz. A iconografia beneficiou-se muito com os mapas confeccionados pelos exímios desenhistas holandeses, nas expedições exploratórias-colonizadoras e com as descrições taxonômicas feitas a partir da criação dos Jardins Botânicos e dos Gabinetes de Curiosidades.

Os catálogos de História Natural é o que restou dos gabinetes e deram grande visibilidade às coleções. A gravura possibilitou um conteúdo descritivo mais fiel e preciso que as ilustrações dos copistas da Idade Média. Tais obras de arte mobilizam idéias acerca da natureza que perpassam o tempo, são apropriadas e reelaboradas por diferentes culturas. Só mesmo o esforço de catalogação deu continuidade ao acervo, colecionado em forma de representações iconográficas que perduraram até os dias atuais.

Nossa leitura de mundo passa necessariamente pela leitura das imagens que guardamos em nossa memória e que funcionam como um repertório visual dos indivíduos. Ao atribuir significados a essas imagens visamos entender os fatores que impulsionam a humanidade na busca da compreensão dos fatos históricos.

Em busca da totalidade, um grande poder foi gradativamente atribuído às imagens. Além do caráter simbólico elas são também fruto do imaginário, construído coletivamente pelos seres humanos através da história. A História Natural se dividiu em outras ciências e hoje a ciência e a arte evoluem para a interdisciplinaridade. Entretanto é o nosso olhar que dá significado ao que vemos com a intenção de compreender a nossa cultura mediada pela ciência e pela arte. E é com o desenvolvimento cultural da humanidade que a história encontra novos caminhos. 